\title{
Methodology to explore emergent behaviours of the interactions between water resources and ecosystem under a pluralistic approach
}

\author{
Glenda García-Santos ${ }^{1}$, Mariana Madruga de Brito ${ }^{2}$, Britta Höllermann ${ }^{2}$, Linda Taft ${ }^{2}$, \\ Adrian Almoradie $^{2}$, and Mariele Evers ${ }^{2}$ \\ ${ }^{1}$ Department of Geography and Regional Studies, Alpen-Adria-University \\ Klagenfurt, Klagenfurt, 9020, Austria \\ ${ }^{2}$ Department of Geography, University of Bonn, Bonn, 53115, Germany \\ Correspondence: Glenda García-Santos (glenda.garciasantos@ aau.at)
}

Received: 28 December 2017 - Accepted: 21 January 2018 - Published: 5 June 2018

\begin{abstract}
Understanding the interactions between water resources and its social dimensions is crucial for an effective and sustainable water management. The identification of sensitive control variables and feedback loops of a specific human-hydro-scape can enhance the knowledge about the potential factors and/or agents leading to the current water resources and ecosystems situation, which in turn supports the decision-making process of desirable futures. Our study presents the utility of a system dynamics modeling approach for water management and decision-making for the case of a forest ecosystem under risk of wildfires. We use the pluralistic water research concept to explore different scenarios and simulate the emergent behaviour of water interception and net precipitation after a wildfire in a forest ecosystem. Through a case study, we illustrate the applicability of this new methodology.
\end{abstract}

\section{Introduction}

The management of water systems is influenced both by physical and social aspects such as hydrology, climate, technological advances, economy, and politics. Nevertheless, while the understanding of the dynamics of the vegetation, soils, and hydrologic processes has greatly improved over the past few decades (Roobavannan et al., 2017; Vose et al., 2011), the complex interactions between social and environmental systems are often ignored (Evers et al., 2017). Part of this complexity arises from the fact that the linkages between human and water systems have often proved difficult to quantify (Patterson et al., 2004), plus existing frameworks for dealing with water management problems are vague, which make them difficult to apply in real case studies (Biswas, 2004).

Despite these challenges, Evers et al. (2017) point out that understanding the co-evolution or interaction of humanwater systems and its social dimensions is essential to effectively tackle the shortcomings in sustainable water manage- ment. Thus, the authors propose the use of a Pluralistic Water Research (PWR) concept, in which key system elements, sensitive control variables, and feedback loops are identified to enhance the knowledge about the potential set of factors that lead to the current water resources and ecosystems situation. This in turn supports the decision-making process of desirable futures.

In forest ecosystems, fires influence the composition and structure of forests, changing the amount of intercepted rainfall and consequently the net precipitation, recharge of aquifers, aesthetics, water and air quality, which increase the costs for society. Hence, knowing how intercepted rainfall and net precipitation rates vary over time and space after such perturbations is required for assessing their social and ecological implications. This is especially relevant in areas with scarce water resources, where a good understanding of the water dynamics is essential for managing water resources in often missing long-term planning strategies and tools (Maddock, 2016). 
Available models of the canopy interception process like Gash (1979) and van Dijk and Bruijnzeel (2001) are designed to predict accumulated net precipitation rates over time. However, how net precipitation rates influence other parameters of the water cycle remained for further research. First attempts to dynamically model rainfall interception are found in Keim and Skaugset (2004) and Keshta et al. (2009). In those models, the re-growth of leaves following a fire and information on the post-fire recovery of the leaf area index (LAI) are not integrated, most presumably because they are rarely empirically studied. Other advances in the original Gash model include the use of measured parameters of forest structure from satellite data (Cui and Jia, 2014). Interestingly, we observe that social aspects are systematically neglected.

To tackle this, approaches that consider the interactions between human and water systems such as the enhanced Driving force-State-Impact-Response (e-DPSIR) (Niemeijer and de Groot, 2008) could be used. To represent processes dynamically the system dynamics (SD) approach is recommended. The SD methodology is based on the understanding of the complex relationships that exist among the different elements within a system (Keshta et al., 2009). The main goal of SD is to comprehend the system and its boundaries by identifying key building blocks, and the proper representation of the physical processes through mathematical relationships (Elshorbagy et al., 2007). Besides its capability for incorporating interdependences between variables, SD-based simulation approaches allow for increased speed of model development, ease of model structure modification, ability to perform sensitivity analysis and effective communication of model results.

This paper aims to model the dynamics of rainfall interception and net precipitation after a human-induced fire under the pluralistic water research (PWR) framework (Evers et al., 2017). We highlight the utility of the SD approach to model the social-physical interlinkages existing in the eDPSIR framework. We explore different scenarios to simulate the emergent behaviour of interception and net precipitation after a wildfire. A case study in La Gomera, Spain, is used to illustrate the applicability of the proposed model.

\section{Methods}

\subsection{Case study: La Gomera island}

The study area comprises La Gomera and its National Park, Garajonay, Spain. The regional climate is characterized by low mean annual precipitation of $660 \pm 247 \mathrm{~mm}$ (GarcíaSantos, 2007, 2012), high relative humidity, mild temperatures $\left(5-7^{\circ} \mathrm{C}\right.$ in winter and $25^{\circ} \mathrm{C}$ in summer) and low insolation due to the frequent presence of clouds. The humid conditions provided by fog enable the occurrence of Laurisilva woodlands on the island. The forest is protected as a national park since 1981 due to its high biodiversity and water resources. Around the park the land use is observed as semi-abandoned areas.

The local culture influences land use, e.g. where quality water is available, consumption as drinking water, leisure, industrial infrastructures and agricultural purposes is ensured, whereas places with a lack of water, risk being abandoned and have a high risk of natural fires such as the wildfire of 2012. La Gomera was selected as the case study because a central human-water research question can be identified after that hazard, i.e. how the conditions of the Laurisilva cloud forest influence water availability for entire ecosystems and human consumption?

\subsection{Modelling approach}

Based on the PWR framework (Fig. 1a) and e-DPSIR approach (Fig. 1b), we identified key elements within the physical human-hydro-scape and human and physical boundaries to understand the effects wildfires on water availability, quality and land use.

We built a dynamic model in STELLA (Systems Thinking, Experimental Learning Laboratory with Animation) software v.9 to understand the dynamics of net precipitation to model the vertical connectivity between atmosphere-plantsoil surface by implementing the Gash model (1979). Furthermore, to consider changes in canopy LAI, we modelled the rainfall interception by vegetation using the framework developed by van Dijk and Bruijnzeel (2001). This model considers that the canopy storage capacity is linearly related to the LAI rather than to the canopy cover. Hence, it allows understanding how intercepted rainfall varies over time.

The initial values used for the modelling parameters (the free throughfall coefficient, the stemflow coefficient, trunk storage capacity $(\mathrm{mm})$, mean rainfall intensity falling onto a saturated canopy $\left(\mathrm{mm} \mathrm{h}^{-1}\right)$, mean wet canopy evaporation rate $\left(\mathrm{mm} \mathrm{h}^{-1}\right)$, specific leaf storage $(\mathrm{mm})$, leaf area index $\left(\mathrm{m}^{2} \mathrm{~m}^{2}\right)$ ) were based on the work of García-Santos (2007). For the extinction coefficient, which depends on leaf distribution and inclination angle, we used the values found by Ross (1975), 0.70. The specific leaf storage was optimized. Furthermore, we assumed that the energy exchange coefficient between the canopy and atmosphere is equal to the extinction coefficient. To simulate the conditions after a fire, the LAI values measured by Bond-Lamberty et al. (2002) after fires were used. Nevertheless, it is important to highlight that the values adopted were calculated for a Boreal Black Forest. Hence, when available, data for Laurisilva forest should be used instead.

Changes in evaporation were not considered due to lack of data but will be addressed in the future. In addition, other elements and connections to water quality and the social scape, i.e. water management, activities and limitations in the $\mathrm{Na}$ tional Park (dashed lines in Fig. 1b), will be included in the dynamic model in the future. Special attention will be given to model fog interception. 
(a)

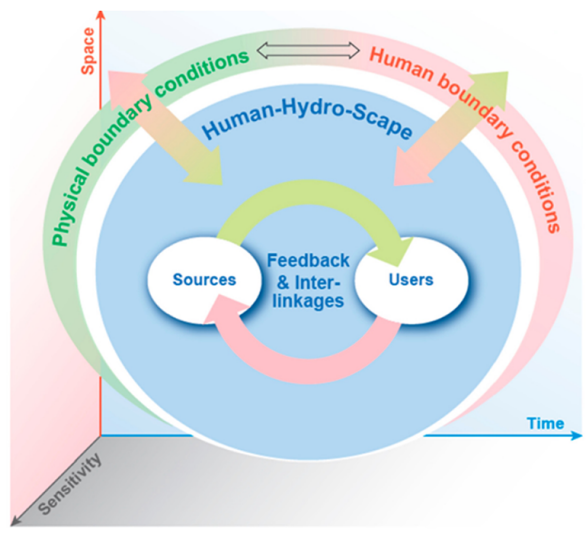

(b)

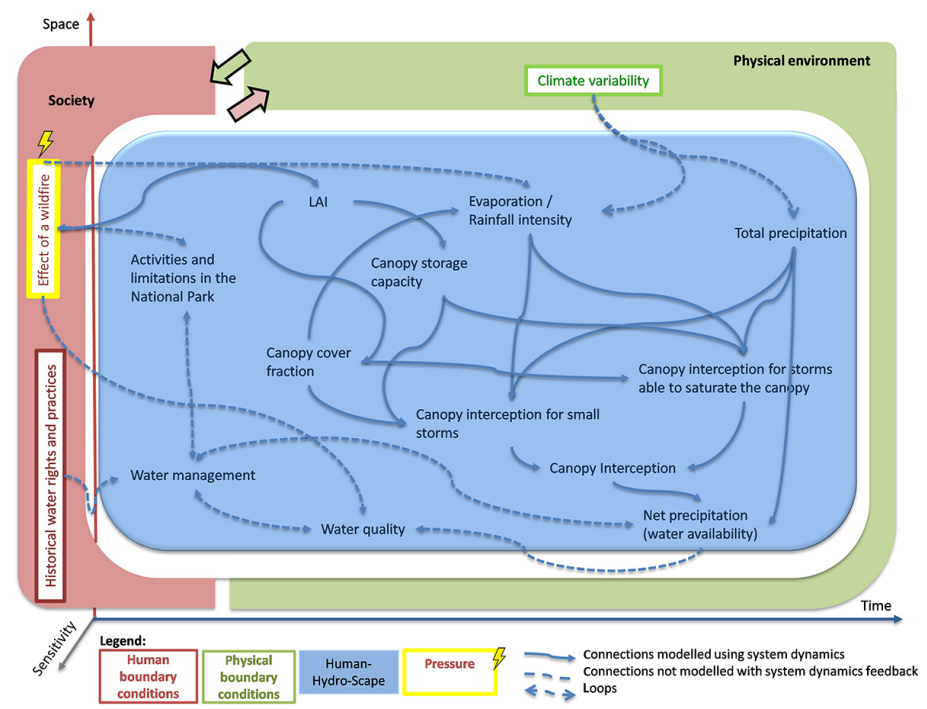

Figure 1. (a) The pluralistic water research (PWR) framework (Evers et al., 2017). (b) Representation of the key elements within the physical human-hydro-scape and human and physical boundaries to understand the effects of human-induced wildfires on rainfall interception, water availability, quality and land use based on the e-DPSIR approach for the case of La Gomera.

\subsection{Model calibration and validation}

Calibration of the two rainfall interception models was conducted daily to obtain the parameters using data measured in 2003 (García-Santos, 2007). For validation, data during 2004 were used (February-September) (García-Santos, 2007). The goodness of fit of measured data was studied through the $r^{2}$. A $r^{2}$ close to 1 expresses a good agreement between measured and predicted data. The Nash-Sutcliffe model efficiency coefficient was calculated. An efficiency of 1 corresponds to a perfect match of simulated to the observed data.

\subsection{Scenarios}

We studied two scenarios. Scenario 1 represents the baseline scenario for those days with precipitation only and modelled canopy interception and net precipitation, whereas scenario 2 represents those variables after a wildfire which sets canopy water interception to zero in the first year and as a function of LAI for the rest of the years. Precipitation inputs were kept as in year 2.

\section{Results and discussion}

\subsection{Canopy interception and net precipitation dynamics under a PWR framework}

Through the new pluralistic water research framework coupled with an e-DPSIR causal change approach, we were able to identify the key elements within the physical humanhydro-scape and human and physical boundaries due to the effect of an induced wildfire (Fig. 1b).

\subsubsection{Key control variables}

After the sensitivity analysis of the model parameters, evaporation was the most sensitive parameter followed by LAI. Interestingly, rainfall intensity had a moderate influence. This highlights the importance of changing evaporative conditions such as solar radiation, air temperature, relative humidity above the canopy and canopy structure.

\subsubsection{Emergent behaviors}

As expected in our still linear model representation, the interlinkages between the continuum atmosphere-plant-soil are evident (Fig. 2). In the year before the fire, the net precipitation was $132 \mathrm{~mm}$ and after the fire it was $153 \mathrm{~mm}$, having the same precipitation inputs due to the interaction between water resources balance and ecosystem variation (LAI). Thus, higher net precipitation is possible because low overstory LAI during the first 3 years allows higher stand drainage. LAI strongly influences energy, water and carbon dioxide exchange between terrestrial ecosystems and the atmosphere (Campbell and Norman, 1998) and at the same time, it is strongly influenced by species, climate, soil fertility, water availability, tree density, evapotranspiration and photosynthesis (in Bond-Lamberty et al., 2002). Changes in net precipitation might be more visible under slightly higher evaporative conditions (most sensitive parameter). Empirical evaporation data after the fire needs to be obtained and incorporated into the dynamic model as well as non-linear relationships. 


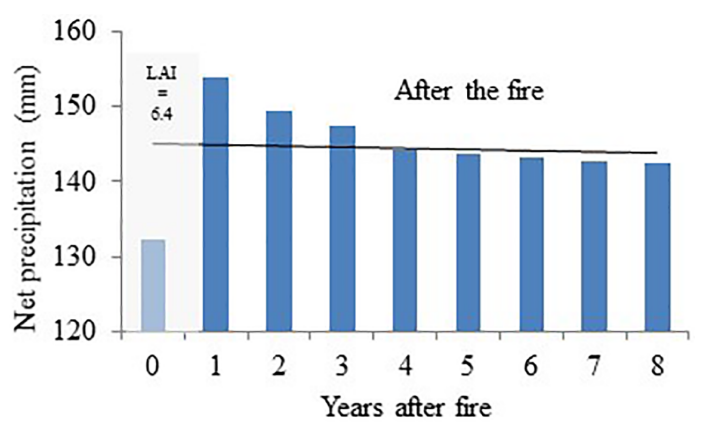

Figure 2. Modeled annual net precipitation before and 8 years after a forest fire after van Dijk and Bruijnzeel (2001) interception model. Precipitation conditions are those measured during 2004. $\mathrm{LAI}=0.7497 \ln (x)+1.6512$ (Bond-Lamberty et al., 2002).

\subsubsection{Feedbacks}

Feedbacks were found between net precipitation and water management, between water quality and wildfire, between water management and activities and limitation in the park and between those and wildfires (Fig. 1b). Though those were not included in the dynamic model due to lack of empirical data, further work will make possible to capture that less water storage in the canopy increases net precipitation in a short-term but decreases net precipitation in a long-term and then decreases again due to the recovery of the woody vegetation.

\subsubsection{Delays}

Delays to growth understory and woody vegetation were modelled and affected canopy interception after the fire following the LAI function (Fig. 2).

\subsubsection{Recovery mechanisms}

Recovery mechanisms of Laurisilva forest, like the fast growth of under story and slow woody vegetation, will have a decisive impact on net precipitation rates. Further work should investigate actual changes of LAI in Laurisilva forest. Opportunities after a fire such as invasive species, changes in physiology should be also investigated in order to incorporate real conditions. The causal changes between water availability, water quality and the human boundary conditions were identified but not modeled. Thus, effects on water quality and land use remain still under work until empirical functions can be derived.

\subsection{Modelled net precipitation}

Cumulative totals of measured and modelled net precipitation are shown in Fig. 3. Modelled interception explained $86 \%$ of the variance of measured interception, with an overall overestimation of $3 \%$. The Nash-Sutcliffe model effi-

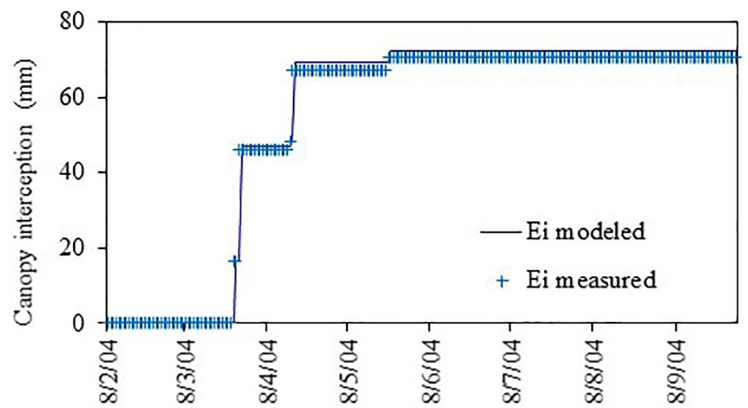

Figure 3. Cumulative measured versus modeled canopy interception data after van Dijk and Bruijnzeel (2001).

ciency coefficient was 0.99 for Gash (1979) and 0.97 for van Dijk and Bruijnzeel (2001). Therefore, both models performed fairly well. The later model was used in the dynamic model. Thus, we were able to model and assess the main dynamics of net precipitation after the wildfire. However, further work needs to include changes in evaporation conditions after a fire, as well as identified feedback loops and water inputs like fog and mixed precipitation (rainfall and fog) in the dynamic model (García-Santos and Bruijnzeel, 2011). This is essential to understand cloud forest dynamics. The causal changes between water availability, water quality and the human boundary conditions were identified but not modeled and therefore some effects remain unknown until empirical functions can be derived.

\section{Conclusions}

This study shows, for the first time, an application of the new pluralistic water research framework coupled with an eDPSIR causal change approach with most of the parameters modeled analytically using SD modeling to explore different scenarios and simulate the emergent behaviour of interception and net precipitation after a wildfire. We studied a baseline scenario for those days with precipitation only and scenario 2 representing the conditions after a wildfire. Frist, we identified the key elements within the physical humanhydro-scape and human and physical boundaries due to the effect of an induced wildfire. Then, after a sensitivity analysis of the analytical model parameters, we founded that evaporation was the most sensitive parameter followed by LAI. Four feedbacks were found between net precipitation and water management, between water quality and wildfire, between water management and activities and limitation in the $\mathrm{Na}$ tional park and between those and wildfires. Using van Dijk and Bruijnzeel (2001), we were able to model and assess the main dynamics of net precipitation after the wildfire. However, actual delays to growth understory and woody vegetation which affect canopy interception after the fire in Laurisilva forest need to be further validated. Thus, so fully understand cloud forest dynamics, the SD model will need to 
include changes in evaporation conditions after a fire, feedback loops and water inputs like fog and mixed precipitation. In the future the causal changes between water availability, water quality and the human boundary conditions will be dynamically modeled and therefore we will gain understanding on the effects of wildfires in the human-hydro-scape.

Data availability. Data used in this study are available on request from the corresponding author, Glenda García-Santos (glenda.garciasantos@aau.at). Data are part of the $\mathrm{PhD}$ thesis of the first author, which is available at http://dare.ubvu.vu.nl/handle/ $1871 / 12697$.

Competing interests. The authors declare that they have no conflict of interest.

Special issue statement. This article is part of the special issue "Innovative water resources management - understanding and balancing interactions between humankind and nature". It is a result of the 8th International Water Resources Management Conference of ICWRS, Beijing, China, 13-15 June 2018.

Acknowledgements. The fieldwork phase to obtain precipitation and throughfall data was carried out by the first author, sponsored by a pre-doctoral scholarship to the first author from the Instituto Nacional de Investigación y Tecnología Agraria y Alimentaria (INIA) of the Ministry of Science and Technology of Spain. The scholarship was to be partly at the Instituto Canario de Investigaciones Agrarias (ICIA) in Tenerife (Canary Islands) within the framework of project RTA01-97. These data are part of the $\mathrm{PhD}$ thesis, which was carried out at VU University, Amsterdam. The authors gratefully acknowledge the support received by the Director from the National Park of Garajonay, Ángel Fernández and the staff from the National Park.

Edited by: Dingzhi Peng

Reviewed by: two anonymous referees

\section{References}

Biswas, A. K.: Integrated Water Resources Management: A Reassessment, Water Int., 29, 248-256, 2004.

Bond-Lamberty, B., Wang, C., Gower, S. T., and Norman, J.: Leaf area dynamics of a boreal black spruce fire chronosequence, Tree Physiol., 22, 993-1001, 2002.

Campbell, G. S., Norman, J. M.: An introduction to environmental biophysics, 2nd Edn., Springer-Verlag Inc., New York, 286 pp., 1998.

Cui, Y. and Jia, L.: A modified gash model for estimating rainfall interception loss of forest using remote sensing observations at regional scale, Water, 6, 993-1012, 2014.
Elshorbagy, A., Jutla, A., and Kells, J.: Simulation of the hydrological processes on reconstructed watersheds using system dynamics, Hydrolog. Sci. J., 52, 538-562, 2007.

Evers, M., Höllermann, B., Almoradie, A., García-Santos, G., and Taft, L.: The Pluralistic Water Research Concept: A New Human-Water System Research Approach, Water, 9, https://doi.org/10.3390/w9120933, 2017.

García-Santos, G.: An ecohydrological and soils study in a montane cloud forest in the National Park of Garajonay, La Gomera (Canary Islands, Spain), PhD Thesis, VU Amsterdam, The Netherlands, available at: https://research.vu.nl/en/publications/ an-ecohydrological-and-soils-study-in-a-montane-cloud-forest-in- $t$ (lsat access: 14 February 2018), 2007.

García-Santos, G.: Transpiration in a sub-tropical ridge-top cloud forest, J. Hydrol., 462-463, 42-52, 2012.

García-Santos, G. and Bruijnzeel, L. A.: Rainfall, fog and throughfall dynamics in a subtropical ridge top cloud forest, National Park of Garajonay (La Gomera, Canary Islands, Spain), Hydrol. Process., 25, 411-417, 2011.

Gash, J. H. C.: An analytical model of rainfall interception by forests, Q. J. Roy. Meteor. Soc., 105, 43-55, 1979.

Keim, R. F. and Skaugset, A. E.: A linear system model of dynamic throughfall rates beneath forest canopies, Water Resour. Res., 40, $1-12,2004$.

Keshta, N., Elshorbagy, A., and Carey, S.: A generic system dynamics model for simulating and evaluating the hydrological performance of reconstructed watersheds, Hydrol. Earth Syst. Sci., 13, 865-881, https://doi.org/10.5194/hess-13-865-2009, 2009.

Maddock, N.: Reducing hazards impacts with smarter spending, Fire Aust., 14-16, available at: https://www.bnhcrc.com.au/ news/2016/reducing-hazard-impacts-smarter-spending (last access: 14 February 2018), 2016.

Niemeijer, D. and de Groot, R. S.: Framing environmental indicators: moving from causal chains to causal networks, Environ. Dev. Sustain., 10, 89-106, 2008.

Patterson, T., Gulden, T., Cousins, K., and Kraev, E.: Integrating environmental, social and economic systems: A dynamic model of tourism in Dominica, Ecol. Model., 175, 121-136, 2004.

Roobavannan, M., van Emmerik, T. H. M., Elshafei, Y., Kandasamy, J., Sanderson, M., Vigneswaran, S., Pande, S., and Sivapalan, M. Norms and values in socio-hydrological models, Hydrol. Earth Syst. Sci. Discuss., https://doi.org/10.5194/hess-2017-432, in review, 2017.

Ross, J.: Radiative transfer in plant communities, in: Vegetation and the Atmosphere, edited by: Monteith, J. L., Academic Press, London, 13-15, 1975.

van Dijk, A. I. J. and Bruijnzeel, L.: Modelling rainfall interception by vegetation of variable density using an adapted analytical model. Part 1. Model description, J. Hydrol., 247, 230-238, 2001.

Vose, J. M., Sun, G., Ford, C. R., Bredemeier, M., Otsuki, K., Wei, X., Zhang, Z., and Zhang, L.: Forest ecohydrological research in the 21st century: what are the critical needs?, Ecohydrology, 4, 146-158, 2011. 